\title{
Pelvic Ectopic Renal Urolithiasis: A Case Report
}

\section{Pelvik Ektopik Renal Ürolitiazis: Olgu Sunumu}

\author{
Umut Gülaçtı', Zülfü Birkan², Cemal Üstün³ \\ 'Harput Devlet Hastanesi, Acil Tıp Kliniği, Elazığ, Türkiye \\ Harput Devlet Hastanesi, Radyoloji Kliniği, Elazığ, Türkiye \\ ${ }^{3}$ Harput Devlet Hastanesi, Enfeksiyon Hastalıkları ve Klinik Mikrobiyoloji Kliniği, Elazığ, Türkiye
}

\section{ABSTRACT}

Ectopic kidney is a congenital malformation which is very rare. The most frequent localisation is in the pelvis. Ectopic kidney is frequently diagnosed incidentally during radiological examination. Because it creates pelvic mass, it can be misdiagnosed as colonic tumours or ureteric masses. In September 2011, a 45-year-old male patient, applied to the emergency service with abdominal pain. On physical examination, there was a left pelvic mass, and left inguinal and left costovertebral sensitivity. In microscopic evaulation of urine, erythrocytes were abundant and the leukocyte value was 3/hpf. Abdominal-pelvic ultrasonography and computed tomography examinations were performed and the patient was diagnosed with an ectopic pelvic kidney and a left ureteral stone. Ureteral stones resulting from an ectopic pelvic kidney are not common. In patients who have applied to the emergency service with abdominal pain, pelvic mass and with no accompanying pathology, a ureteral stone as a result of an ectopic pelvic kidney may be considered as not requiring treatment.

Keywords: Congenital malformation, ectopic kidney, pelvic region, urolithiasis

Received: 07.10.2011 Accepted: 01.12.2011

\section{ÖZET}

Ektopik böbrek nadir görülen bir konjenital malformasyondur. En sık görülen lokalizasyon pelvistir. Ektopik böbrek sıklıkla radyolojik tetkikler esnasında tesadüfen saptanırlar. Pelvik bölgede kitle oluşturduğu için kolon tümörleri ve üreter kaynaklı kitleler ile karıştıılabilirler. Eylül 2011'de, 45 yaşında bir erkek hasta acil servise karın ağrısı ile başvurdu. Fizik muayenesinde, sol pelvik bölgede kitle ve sol inguinal bölgede hassasiyet ve sol kostovertebral açı hassasiyeti mevcuttu. İdrar mikroskopisinde her büyük büyütme alanında bol eritrosit ve 3 lökosit görüldü. Batın-pelvik ultrasonografi ve bilgisayarlı tomografi çekilerek pelvik ektopik böbrekte üreter taşı tanısı konuldu. Pelvik ektopik böbrek ürolitiazisi sık karşılaşılan bir durum değildir. Acil servise karın ağrısı ve kitle nedeniyle başvuran hastalarda tanıda, ek bir patoloji olmadığı takdirde tedavi gerekmeyen, pelvik ektopik böbrek ürolitiazisi olabileceği düşünülmelidir.

Anahtar Kelimeler: Konjenital malformasyon, renal ektopi, pelvis, ürolitiazis

Geliş Tarihi: 07.10.2011 Kabul Tarihi: 01.12.2011

\section{Giriş}

Matür böbreğin renal fossa dışında bir yerde bulunmasına renal ektopi denir (1). Renal ektopi, fetal kalıcı böbreklerin pelvist en üst retroperitoneal bölgeye göç edememesi sonucu oluşur (2). İnsidansı yaklaşık 1/2000-3000'dür. Ektopik olan böbrek normalden küçük ve fetal lobulasyona bağlı olarak farklı şekillerde olabilir. Üreterin mesaneye girişi normal yerindedir. Sağ ve sol böbrekte eşit sıklıkta oluştuğu ve cinsiyet farkı görülmemektedir (3). Renal ektopiler; torasik, yukarı abdominal, aşağı abdominal, iliak, pelvik ve karşı taraf lokalizasyonlu olabilir. En sık görülen lokalizasyon \%55 oranında pelvistir (4).

Pelvik ektopik böbrek vakalarında ürolitiazis gelişimi bilinen bir durum olmasına rağmen acil servise başvuran hastalarda pelvik kitle ve karın ağrısının nadir bir sebebi olabileceğini vurgulamak istedik. 


\section{Olgu Sunumu}

Acil servisimize karın ağrısı nedeniyle başvuran, özgeçmiş ve soy geçmişinde özellik olmayan 45 yaşında erkek hastanın fizik muayenesinde kan basıncı 130/70 mm/Hg, ateş $37^{\circ} \mathrm{C} / a k s i l l e r$, batında sol inguinal bölgede hassasiyet ve sol pelvik bölgede derin palpasyonla sert kıvamlı kitle vardı. Sol kostovertebral açı hassasiyeti mevcuttu. Rebound ve defans yoktu. Laboratuar tetkiklerinde beyaz küre normal değerlerde, idrar mikroskopisinde her büyük büyütme alanında bol eritrosit ve 3 lökosit görüldü. İdrar kültürü alındı. Sol pelvisteki tümoral kitle nedeniyle yapılan batın-pelvik ultrasonografisinde (USG); sol böbrek pelvise ektopik yerleşimli, pelvikaliksiyel yapıları belirgin dilate görünümdeydi (Resim 1). Hastaya pelvikaliksiyel dilatasyon ve ürolitiazis açısından batın-pelvik tomografi (BT) planlandı. Çekilen batın-pelvik BT'de sağ böbrek normal lokalizasyonunda, sol böbrek pelvik yerleşimli olup toplayıcı sistemi belirgindi. Ayrıca pelvis alt kesitinde sol üreter lokalizasyonunda $6 \mathrm{~mm}$ boyutlu hiperdens üreter taşı izlendi (Resim 2a, b).

Hastada mevcut olan renal kolik için acil serviste diklofenak sodyum 75 mg ampul ve hiyosin-N-butil bromür 20 mg ampul intramusküler yoldan yapıldı. Hastanın kolik ağrısı azaldı. İdrar yolu enfeksiyonu için Enfeksiyon Hastalıkları Kliniğinden konsültasyon istendi. İdrar yolu enfeksiyonu için hastaya siprofloksasin 500 mg tb 2x1 oral ampirik antibiyotik tedavisi başlandı. Pelvik ektopik böbrek taşı açısından üroloji konsültasyonu istendi. Konsültasyon sonucunda hastanemizde Extracorporeal ShockWave Lithotripsy (ESWL) ve perkütan nefrolitotomi (PNL) yapılamadığı için hasta ileri bir merkeze sevk edilmesi önerildi. Sonraki incelemelerde idrar kültüründe üreme olmadığı saptandı.

\section{Tartışma}

Ektopik böbrek nadir görülen bir konjenital malformasyondur (1). Ektopik böbrek sıklıkla asemptomatiktir. Radyolojik tetkikler esnasında tesadüfen saptanırlar. Genitoüriner sistem anomalileri ektopik böbrekle birlikte görülebilir. Gastrointestinal sistem, iskelet sistemi ve kardiyovasküler sistem ile ilgili anomaliler de saptanmıştır (1, 4). Sunduğumuz olguda ise pelvik ektopik böbrek dışında ek bir anomali söz konusu değildi.

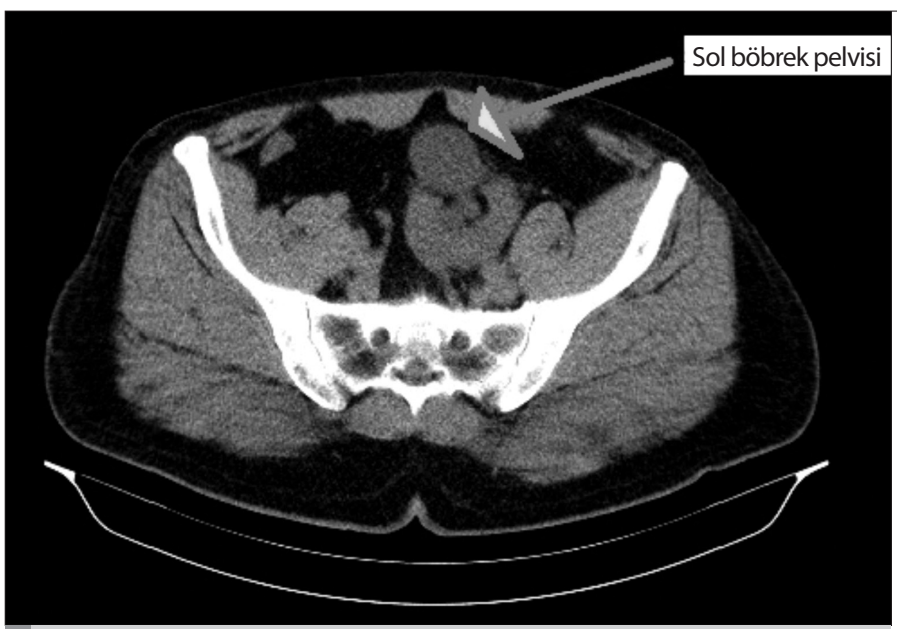

Resim 2a. Batın-Pelvik tomografi: Sol pelvik ektopik böbrekte pelvikaliksiyel genişleme
Ektopik böbrekler, rotasyon anomalileri nedeniyle idrar drenajı yetersizliğine bağlı olarak üriner enfeksiyonunun gelişimine duyarlıdırlar ve pelvik ektopik böbrekte normal böbreğe göre üriner sistemde taş ve hidronefrozu daha sık görülür $(1,3,4)$. Semptomatik vakalarda en sık görülen yakınma taş oluşumuna bağlı karın ağrısıdır $(4,5)$. Sunulan olguda da pelvik ektopik böbrekte taş oluşumu meydana gelmiş olup hastanın acil servise geliş yakınması karın ağrısı idi. Üriner sistem taşlarında karın ağrısı kolik tipte olup insanlarda hissedilen en şiddetli ağrılardan biridir ve dolayısıyla acil tedavisi gerekir. Bu amaçla antimuskarinik etkiyle üreterde düz kas gevşemesine sebep olan hiyosin-N-butil bromür eskiden beri kullanılmaktadır. Yine günümüzde bu amaçla en çok kullanılan ilaç grubu ise non-steroid antienflamatuar ilaçlardır (NSAii). Bunların içerisinde en çok tercih edileni diklofenak sodyumdur ve intramusküler uygulanmaktadır (6). Sunduğumuz olguda da hastanın kolik ağrısı için acilde bu tedavi şekli uygulanarak başarılı sonuç alındı.

Pelvik ektopik böbrek; pelviste kitle oluşturan gastrointestinal sistem kaynaklı kolon kanserleri, üreter kaynaklı kitleler ve kadınlarda adneksiyal kitleler ile karıştırılabilir $(3,7)$. Sunduğumuz olguda da aci-

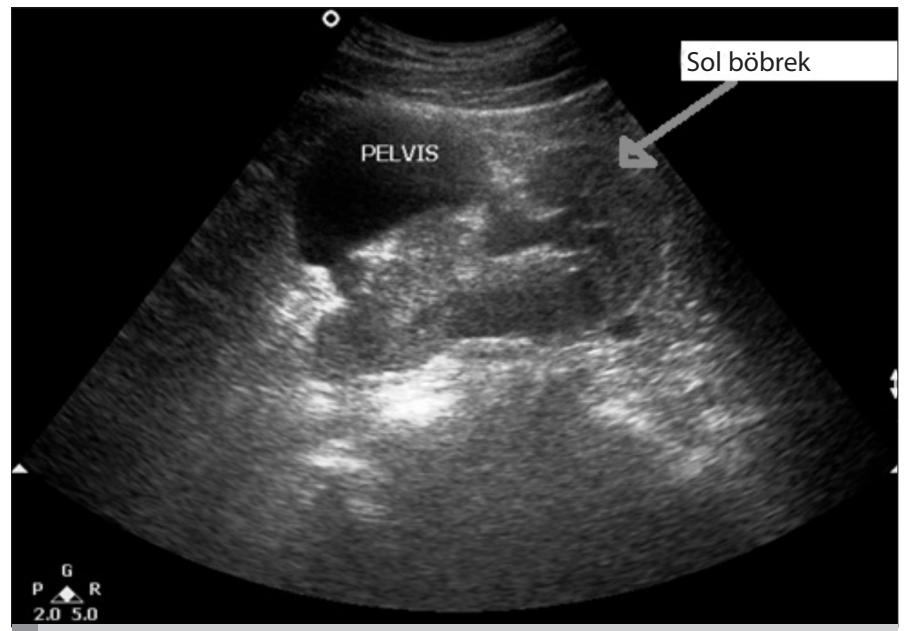

Resim 1. Batın-Pelvik USG: Sol pelvik ektopik böbrek

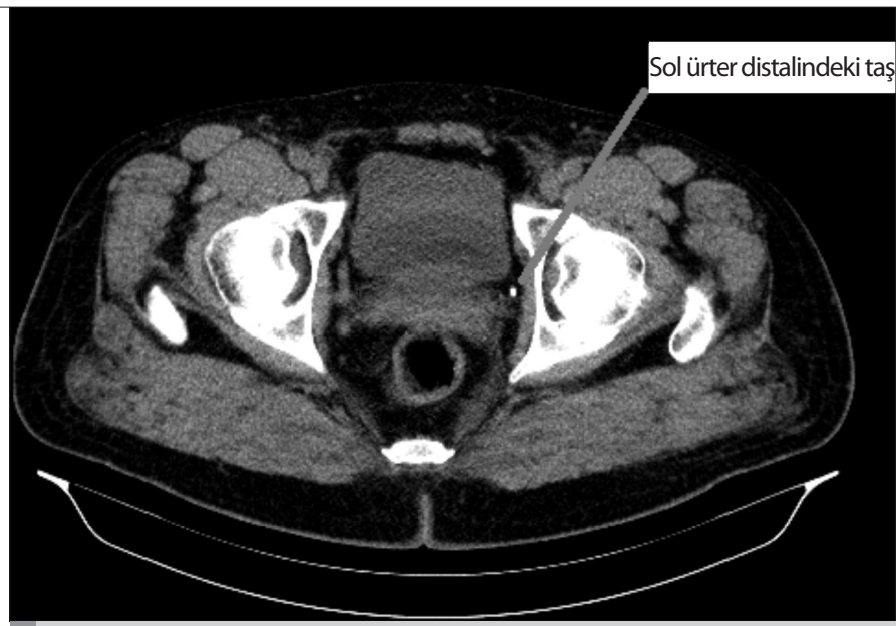

Resim 2b. Batın-Pelvik tomografi: Sol üreter distalindeki taş görünümü 
le ilk gelişte ön tanı olarak pelvik tümoral kitle düşünülmüştü. Fakat daha sonraki radyolojik tetkikler sonucunda, pelvik kitlenin nadir bir sebebi olan pelvik ektopik böbrek tanısı konmuştur.

Üriner sistem taşlarında teorik olarak çapı 5 mm altındaki taşların düşebileceği görüşü kabul edilmektedir. Daha büyük çaplı olan üriner sistem taşlarının tedavisinde ESWL, açık cerrahi ve PNL gibi endoskopik tedaviler uygulanabilir. Pelvik ektopik böbrek taşlarının tedavisinde ESWL uygulanması pelvisteki birçok çevre dokuya zarar verebilir. Üriner sistem taşlarının tedavisinde PNL uygulaması ise; taş boyutunun 2 cm'den büyük olması, sistin, kalsiyum oksalat monohidrat gibi sert taşların olması, enfeksiyon varlığı, ESWL kontrendikasyonu ya da başarısızlığı, böbreğin anatomik varyasyonları olan at nalı böbrekte, transplante böbrekte ve ektopik böbrekte taş oluşumu endikasyonlarında öncelikli tercih edilmelidir $(8,9)$. Sunduğumuz olguda hastada pelvik ektopik böbrek anatomik varyasyonu olduğu için PNL yapılması gerekebileceğinden ileri bir merkeze sevk edilmiştir.

\section{Sonuç}

Pelvik ektopik böbrek taşları acil servislerde sık karşılaşılan bir durum değildir. Karın ağrısı ile acil servise gelen hastalarda, pelvik ektopik böbrek ürolitiazisi ayırıcı tanı içerisinde düşünülmesi gereken bir durumdur. Pelvik kitle tespit edilen hastalarda kitlenin asıl sebebinin pelvik ektopik böbrek olabileceği akılda tutulmalıdır.

\section{Çıkar Çatışması}

Yazarlar herhangi bir çıkar çatışması bildirmemişlerdir.

\section{Kaynaklar}

1. Walsh PC, Gittes RF, Perlmutter AD, Stamey TA: Anomalies of the Upper Urinary Tract. Campbell's Urology. 5th ed. Philedephia: W.B Saunders Company; 1986.p.1665-741.

2. Hiroaka M. Medical management of congenital anomalies of the kidney and urinary tract. Pediatr Int 2003; 45: 624-33. [Crossref]

3. Cinman NM, Okeke Z, Smith AD. Pelvik kidney associated diseases and treatment. J Endourol 2007; 21: 836-42. [Crossref]

4. Coplen DE. Developmental and positional anomalies of the kidney. In: Pediatric Surgery, Ashcraft KW, Murphy JP, Sharp RJ, Sigalet DL, Snyder CL, Eds. 4th ed. Philadelphia: WB Saunders Company; 2000.p.681-9.

5. Guarino N, Tadini B, Camardi P, Silvestro L, Lace R, Bianchi M. The incidence of associated urological abnormalities in children with renal ectopia. J Urol 2004; 172: 1757-9. [Crossref]

6. Menon M, Resnick MI. Urinary lithiasis: Etiology, diagnosis and medical management. In Walsh, Retik, Vaughan and Wein Editor. Campbell's Urology. 8th ed. Philadelphia:WB Saunders; 2002.p.3229-306.

7. Fleischer AC. Pelvik Kitlelerin Transabdominal ve/veya Transvaginal sonografi ile değerlendirilmesi, In: Fleischer AC, Manning FA, Jeanty P, Romero R Eds. Obstetrik ve Jinekolojide Sonografi Prensipler ve Klinik Uygulamalar, Çev. Edit:Yüksel A, İstanbul: Ulusal Tıp Kitabevi;1996.p.767.

8. Öner A. I.Ü. Cerrahpaşa Tıp Fakültesi Sürekli Tıp Eğitimi Etkinlikleri Üriner Sistem Taş Hastalığı. Sempozyum Dizisi. No:68 2009.p.19-40.

9. Goel R, Yadav R, Gupta NP, Aron M. Laparoscopic assisted percutaneous nephrolithotomy (PCNL) in ectopic kidneys: Two different techniques. Int Urol Nephrol 2006; 38: 75-8. [Crossref] 